\title{
CHARACTERIZATION OF HUMAN CYP450 ISOZYMES RESPONSIBLE FOR THE IN VITRO OXIDATIVE METABOLISM OF MESALAMINE USED FOR COLITIS

\author{
Elif Kale $^{1}$, Alaattin Şen ${ }^{2}$
}

\begin{abstract}
Mesalamine [5-aminosalicylic acid (5-ASA)] is a substantial supportive agent in the treatment of inflammatory bowel diseases (IBD), particularly in ulcerative colitis (UC). It is well known that 5-ASA is metabolized by phase II enzymes. And most likely cytochrome P450 enzymes have an important role in this process. However, there is no information to the accuracy of this and which CYP isoforms affect this potential pathway of metabolism. In this study, it was aimed to find out whether other alternative drug metabolism pathways other than $\mathrm{N}$-acetylation, are involved in 5-ASA metabolism, particularly cytochrome P450s. For this purpose, first, a colorimetric method was developed to measure the 5ASA. Then, it was applied to determine whether mesalamine was metabolized by in vitro with each pure CYP450 isozymes (CYP1A2, CYP2C9, CYP3A4, CYP2C19, CYP2D6). It has shown that 5-ASA acted as a substrate for the CYP3A4 and CYP2D6 isoforms. The incubation of pure CYP isoforms in the presence of prototype substrates together with 5-ASA have led to inhibition of prototype activities of CYP3A4 and CYP1A2. As a consequence, this study demonstrated that the 5-ASA is both a substrate and an inhibitor for CYP3A4, a substrate for CYP2D6, and an inhibitor for CYP1A2. Thus, the prescription of mesalamine together with the drugs metabolized with these CYP isozymes could cause unanticipated adverse reactions or therapeutic failures. These are the new contributions to the literature.
\end{abstract}

UDC Classification: 615, DOI: 10.12955/cbup.v7.1450

Keywords: Mesalamine 5-Aminosalicylic acid (5-ASA), CYP3A4, CYP2D6, CYP1A2, Metabolism, Drug metabolizing enzymes, Drug-drug interactions

\section{Introduction}

In the United States (USA) and Europe, nearly 1.4 million and 2.2 million people respectively suffer from various inflammatory bowel diseases (IBD), particularly UC and Crohn's disease (CD) (Loftus, 2004). Mesalamine or 5-ASA is the main agent used in the treatment of IBD for many years and remains indispensable for treatment in patients with mild to moderate UC (Bergman et al., 2006; Watkinson, 1986). According to information from the National Institutes of Health from the 2004 Verispan database of prescriptions filled in the USA, $44 \%$ of the drugs used for the treatment of CD patients and $81 \%$ of the drugs used for UC patients were 5-ASA (Everhart, 2008). The first 5-ASA prodrug, sulfasalazine, was developed by Professor Nana Svartz for the treatment of rheumatoid arthritis in the 1940s. The empirical formula of the 5-ASA molecule is $\mathrm{C}_{7} \mathrm{H}_{7} \mathrm{NO}_{3}$ and has a molecular weight of $153.135 \mathrm{~g} / \mathrm{mole}$ shown in fig. 1 .

\begin{tabular}{|l|}
\hline Figure 1: Chemical structure of 5-ASA \\
\hline Source: Sigma-Aldrich (Merck) \\
\hline
\end{tabular}

5-ASA is primarily active in the colonic mucosa from the luminal side, and its local anti-inflammatory effect is here and associated with mucosal concentrations. Several mechanisms, such as inhibition of intestinal macrophage chemotaxis (Nielsen et al., 1988), inhibition of proinflammatory cytokine release (Galvez et al., 2003), inhibition of cyclooxygenase and prostaglandin pathways (Hawkey et al., 1985), inhibition of nuclear factor-kB activation (Egan et al., 1985) and others (Reifen et al., 2004; Rousseaux et al., 2005; Horvath et al., 2008) have been proposed to better understand how this effect is induced.

5-ASA is metabolized to N-acetyl-5-ASA which is the first active metabolite of 5-ASA by $\mathrm{N}$ acetyltransferases (NAT) expressed in colon epithelial cells. NATs are enzymes that can perform acetyl transfer from acetyl-coenzyme A (Ac-CoA) which is a type of acetyl donor (Allgayer et al.,

\footnotetext{
${ }^{1}$ Faculty of Arts and Sciences, Department of Biology, Pamukkale University, Denizli, Turkey, elifkale89@gmail.com

${ }^{2}$ Faculty of Life and Natural Sciences, Department of Molecular Biology \& Genetics, Abdullah Gül University, Kocasinan, Kayseri, Turkey, sena@ pau.edu.tr
} 
1989; Ireland et al., 1990; Nielsen et al., 2007). These enzymes are involved in phase II xenobiotic metabolism. The effect of 5-ASA absorbed in the small intestine is $\mathrm{pH}$ and time-dependent. It is converted into an inactive form and can be excreted in the urine (Tjornelund et al., 1991; Dilger et al., 2007) (Fig. 2).

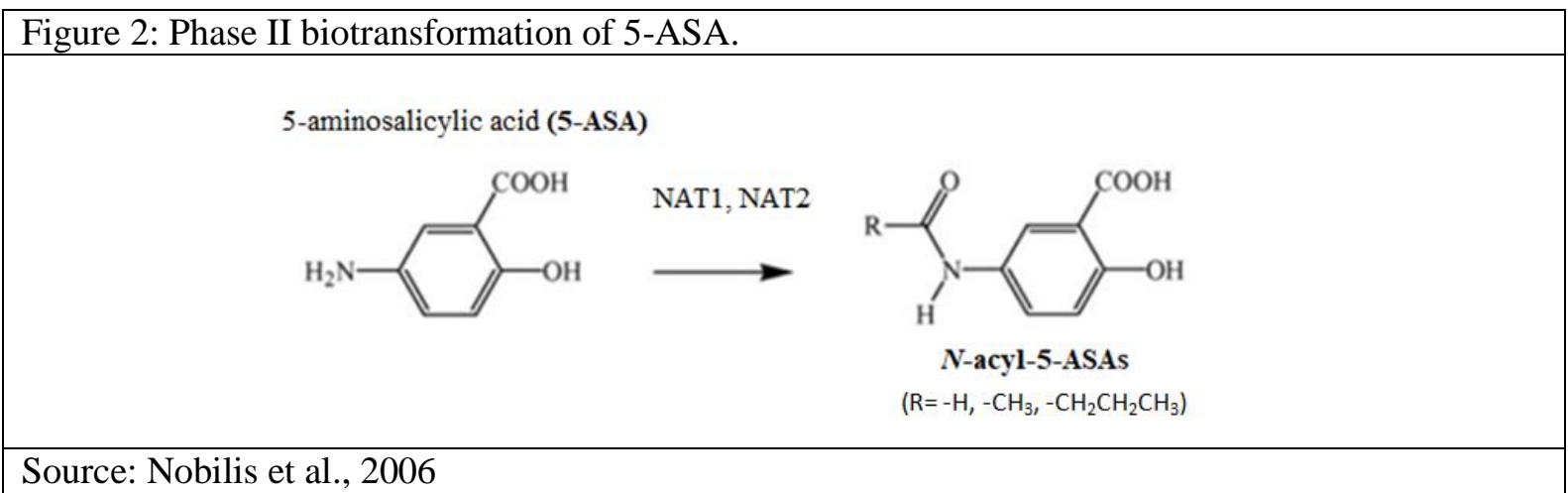

Cytochrome P450 (CYP) enzymes are the main phase I enzyme family involved in the oxidative metabolism of steroids, fatty acids, prostaglandins, and many other natural compounds, as well as carcinogens, mutagens, drugs, xenobiotics. It explains why these enzymes are of particular importance for clinical pharmacology (Nelson, 2004; Guengerich, 2008; Zanger et al., 2008). Cytochrome P450 1A2 (CYP1A2), a well-known aryl hydrocarbon hydroxylase, has high levels in the liver $(\sim 4-16 \%$ / total hepatic CYP enzyme content) (Nelson et al., 2004; Wang et al., 2009). Drug-drug interactions should be considered in drug therapy with substrates of the enzyme CYP1A2, which take an active role in the metabolism of many xenobiotics because the flexibility of binding of the active site of the enzyme to different surfaces can lead to reversible or irreversible inhibition of the enzyme. Some of the strongest inhibitors are furafylline and $\alpha$-naphthoflavone (Hiemke and Härtter, 2000). CYP2C9 constitutes $20 \%$ of the total CYP enzymes found in the liver (Shimada et al., 1994). For CYP2C9, the most abundant CYP enzyme in the liver, the best-known drug substrates are weak acids containing carboxylic groups in their structures. CYP2C9 metabolizes more than 100 clinical drugs (hydroxylates) including nonsteroidal anti-inflammatory drugs such as ibuprofen, oral hypoglycemic agents such as tolbutamide, antiepileptic drugs such as phenytoin, oral anticoagulant couzidine (Lee et al., 2002; Rettie and Jones, 2005). Being the first CYP2C enzyme discovered by its genetic polymorphism, CYP2C19 antiulcer is responsible for the oxidative biotransformation of many drugs including various drug groups such as those belonging to anticancer, antidepressant, antihypertensive and antiplatelet drugs (Küpfer and Preisig, 1984; Brøsen, 2004). Although the CYPs constitutes 2\% of the enzymes in the liver, CYP2D6 is involved in the oxidative metabolism of more than 70 pharmaceuticals. This enzyme, which is also found outside the liver, has been found to be similar to the hepatic enzyme in the brain and is associated with dopamine transport. It plays a role in the metabolism of antidepressants, antihistamines, antidiabetic, antipsychotic drugs (Zanger et al., 2008; Stingl et al., 2013). Among the P450s, CYP2D6 is the only on-inducible enzyme, which results in a substantial contribution of genetic variation to the inter-individual variation in enzyme activity (Owen RP et al., 2009). CYP3A4, which catalyzes N-dealkylation reactions, is the most active among the CYP450 enzymes involved in drug metabolism. CYP3A4, which catalyzes N-dealkylation reactions, is the most active CYP450 enzyme that metabolizes almost 30\% of clinically used drugs in CYP450 enzymes involved in drug metabolism (Bu, 2006; Liu et al., 2007; Zanger et al., 2008). Thanks to its flexible and large active side, CYP3A4, provide to metabolize large drugs such as of cyclosporine A, tacrolimus-erythromycin, and taxol, but also smaller drugs such as tamoxifen, benzodiazepines, and opioids (Scott and Halpert, 2005; Hendrychová et al., 2011).

Therefore, the present study is aimed to identify the cytochrome P450 isozymes responsible for the alternative oxidative metabolism of mesalamine other than major $\mathrm{N}$-acetylation.

\section{Methods}

\section{Measurement of 5-ASA Activities of CYP Isoforms}

In the spectrophotometric measurement of 5-ASA, 5-ASA was reacted with nitrite in an acidic medium to form the corresponding diazonium salt. After the nitrite residues due to the side reactions 
were removed with sulfamic acid which reacts faster than urea, the diazonium salt was combined with the phloroglucinol reagent in the alkaline medium. Yellow-orange and water-soluble azo dye formed by combining the diazotized 5-ASA and phloroglucinol reagent in an alkaline medium and was measured at 430nm. The method was inspired by Hamdon (2011) and was optimized.

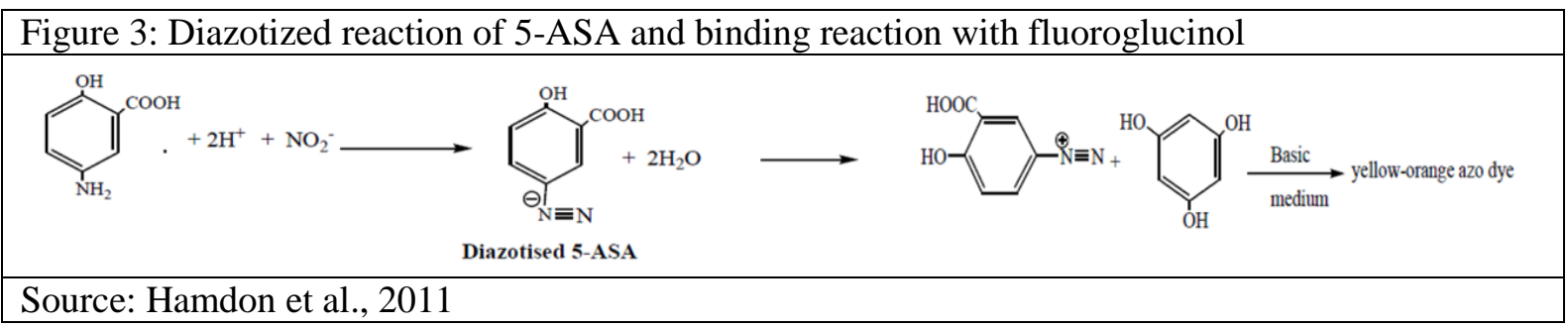

The metabolism of 5-ASA with each pure CYP isozyme (cerosomes) was measured by the colorimetric method in which the concentration of 5-ASA was calculated indirectly. In order to determine the activity of the CYPs isozymes on 5-ASA, they were incubated with the pure CYP enzymes (cerosomes prepared from Saccharomyces cerevisiae expressing the human cytochrome P450 isozyme and human NADPH reductase) in the presence of NADPH for $60 \mathrm{~min}$ at $37{ }^{\circ} \mathrm{C}$, and the remaining 5-ASA was measured as described above. The standard curve derived with use of pure 5ASA was used to calculate the enzyme activity. Microsomal CYP1A2-dependent methoxyresorufin Odemethylase (MROD) activities were assayed by the method of Burke and Mayer (1974), as optimized by Sen and Arinç (2000). CYP3A4-dependent erythromycin N-demethylase (ERND) activity was determined by measuring the quantity of formaldehyde formed according to Nash (1953) and modified by Cochin and Axelrod (1959). Similarly, CYP2C9/19-dependent aminopyrine N-demethylase activity was determined by the method proposed by Cochin and Axelrod (1959) and by measuring the amount of formaldehyde according to the Nash (1953) method. The activity measurement was also performed in the presence of prototype CYPs inhibitors to validate the activity measurement (CYP1A2Furafylline, CYP2C19-Omeprazole, CYP2C9-Sulfaphenazole, CYP3A4-Ketoconazole).

\section{Results}

According to the 5-ASA-CYP activity measurement based on the reading of the intensity of the color formed when the 5-ASA and pure CYP450 enzymes were incubated, it was found that 5-ASA was not metabolized by CYP1A2, CYP2C9, CYP2C19 enzymes. Also, the activities of CYP2D6 and CYP3A4 enzymes were determined as $0.280 \pm 0.04$ pmoles 5-ASA consumed $/ \mathrm{min} / \mathrm{pmole}$ CYP3A4 and $0.228 \pm$ 0.09 pmoles 5-ASA consumed/min/pmole CYP2D6, respectively. Moreover, it could be speculated that CYP3A4 plays a role in the 5-ASA metabolism. The activity values calculated as a result of incubation of 5-ASA with pure CYP enzymes are given in Table 1 as pmoles 5-ASA consumed per minute per pmole CYP.

The effect of 5-ASA on the CYP1A2-associated methoxyresorufin O-demethylase (MROD) activity, CYP3A4-associated erythromycin N-demethylase (ERND) activity and CYP2C9/19-dependent aminopyrine $\mathrm{N}$-demethylase activity, alongside with the prototype inhibitors of each enzyme are presented in fig. 4.

\section{Discussion}

5-ASA is an agent that has been used for the treatment of IBD, especially ulcerative colitis, and has an anti-inflammatory effect. 5-ASA is metabolized to N-acetyl-5-ASA in the colon by NATs. However, the absorption of 5-ASA from the colon is only minimal. There is no information on the effect of 5ASA on cytochrome P450 enzymes which play the most active role in drug metabolism and the role of these enzymes in the oxidative metabolism of 5-ASA. In many reported studies, methods including mass spectroscopy, high-performance liquid chromatography, micellar electrokinetic chromatography were used to determine 5-ASA. Besides, various spectrophotometric methods are of 5-ASA and which are used for the determination of 5-ASA. The current study involved the use of colorimetric measurement of 5-ASA to determine the involvement of CYP450 enzymes in the oxidative metabolism of 5-ASA, by using pure enzymes as ceresomes. In addition, the effects of 5-ASA on the activity of pure CYP isoenzymes with their prototype substrates alongside known prototype inhibitors were also determined for further characterizations. 


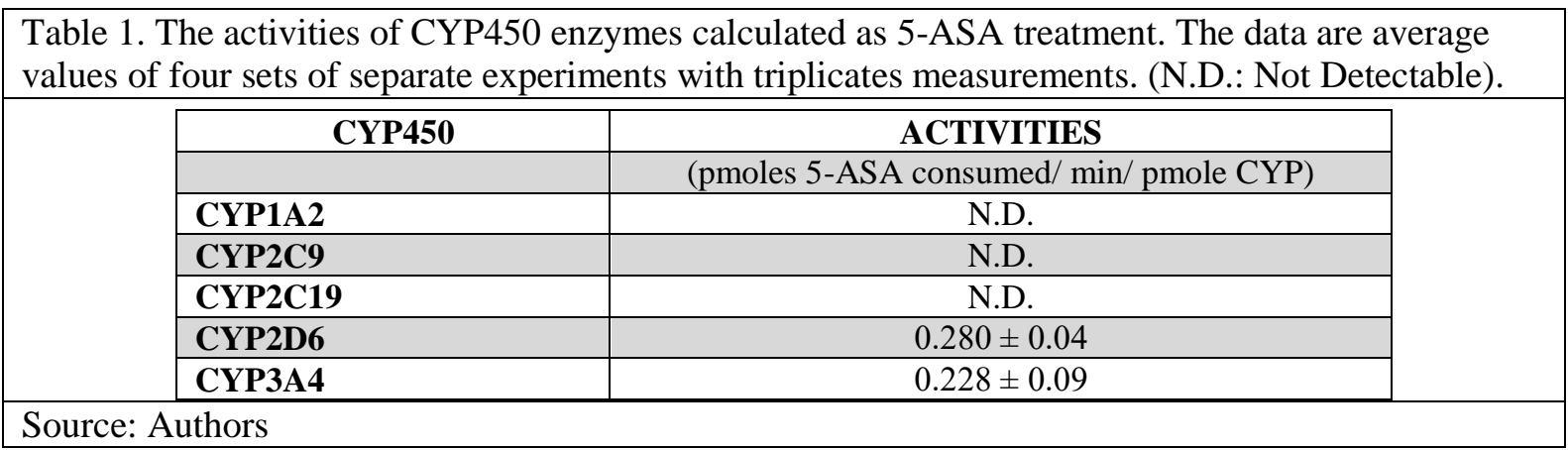

Figure 4: Determination of the effect of 5-ASA run alongside the prototype inhibitors on the CYP isozymes-associated prototype activities (MROD, APND and ERND).

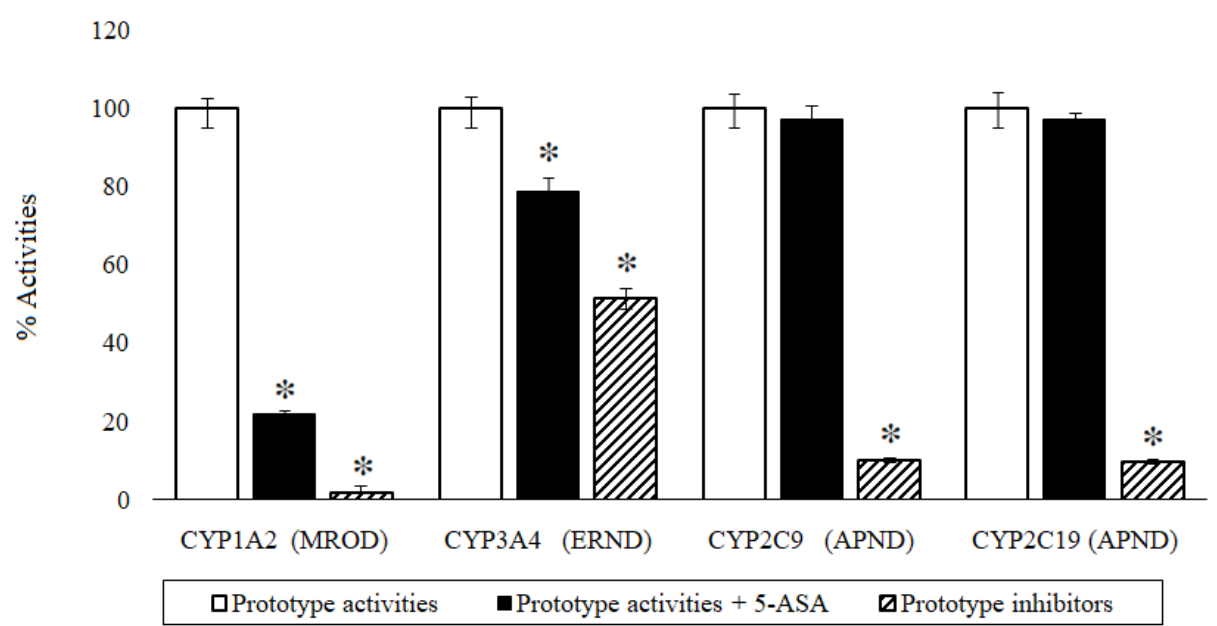

The data are the mean values of 4 sets of independent experiments with triplicates measurements. *Significantly different from the respective control values $P<0.05$.

Source: Authors

According to the results of the described method based on the reading the intensity of the color formed when the 5-ASA and pure CYP450 enzymes were incubated, 5-ASA was metabolized by CYP2D6 and CYP3A4 enzymes. The activities of CYP2D6 and CYP3A4 enzymes were determined as $0.280 \pm 0.04$ pmoles 5-ASA consumed/min/pmole CYP2D6 and 0.228 \pm 0.09 pmoles 5-ASA consumed/min/pmole CYP3A4, respectively. Thus, it is strongly suggested that these enzymes play a role in the oxidative metabolism of 5-ASA.

When CYP3A4-associated erythromycin N-demethylase (ERND) activity was measured in the presence of 5-ASA, the ERND activity was decreased to $20 \%$ as compared to ERND activity in the absence of 5-ASA. The percentage ERND activity was reduced by almost 50\% when CYP3A4associated ERND activity measured in the presence of the prototype inhibitor of the enzyme, i.e., ketoconazole. The inhibitory effect of 5-ASA is much higher than the prototype inhibitor. Furthermore, another activity measurement study that was performed in our laboratory before, again showed that ERND activity was significantly inhibited by 5-ASA incubation with erythromycin (Yasar et al., 2011) In the same study, CYP3A4 mRNA expression level after 5-ASA treated HeLa cell line showed that CYP3A4 mRNA expression level increased by $40 \%$ at $48 \mathrm{~h}$ compared to the control. Similarly, Kim and coworkers (2015) have also shown that 5-ASA induced CYP3A4 activity along with mRNA expression level in the culture of human cryopreserved hepatocytes. Thus, these results strongly suggest that 5-ASA could be both a substrate and an inhibitor for the CYP3A4 enzyme. Also, 5-ASA is likely to produce competitive inhibition, but further detailed examinations are required to support this suggestion. 
Although the activity measurement method used in our previous study shows that there is $36 \%$ inhibition of CYP2C9-associated aminopyrine N-demethylase (APND) activity in the presence of 5ASA, the present study shows that there was no change in the activities of CYP2C $9 / 19$-associated aminopyrine N-demethylase (APND) in the presence of 5-ASA as compared to APND activity in the absence of 5-ASA. Thus, CYP2C9/19 might not be involved in the oxidative metabolism of 5-ASA.

CYP1A2 was about $80 \%$ CYP1A2 catalyzed and MROD activity was completely blocked when the enzyme was incubated with its prototype inhibitor furafylline. These data are strongly indicating that 5-ASA may have an inhibitory action on the CYP1A2 enzyme.

As a result, 5-ASA was metabolized with CYP3A4 and interestingly with CYP2D6, which of these two CYPs are known to metabolize more than 55\% of the known drugs prescribed. In addition, 5-ASA was identified to be an in vitro inhibitor for both CYP1A2 and CYP3A4 enzymes. These data are significant and are first reports for the literature according to our knowledge. The fact that P450 enzymes expression levels are affected by 5ASA and P450 enzymes and may be involved in 5-ASA metabolism indicate that special care must be taken for the drugs prescribed regarding drug-drug interactions and intoxications for patients using 5-ASA such as IBD and UC patients. A similar situation applies to CYP2D6 and CYP1A2 and considering that these patients use 5-ASA, it is clear that potential drug-drug interactions can be dangerous.

\section{Conclusions}

In conclusion, the present study presents compelling pieces of evidence indicating that the 5-ASA is both a substrate and an inhibitor for CYP3A4, a substrate for CYP2D6, and an inhibitor for CYP1A2. Thus, the prescription of mesalamine together with the drugs metabolized with these CYP isozymes could cause unanticipated adverse reactions or therapeutic failures. These are the new contributions to the literature.

\section{Acknowledgments}

This work supported by Pamukkale University PAUBAP-2015FBE042.

\section{References}

Allgayer, H., Ahnfelt, NO., Kruis, W., et al. (1989). Colonic N-acetylation of 5-aminosalicylic acid in inflammatory bowel disease. Gastroenterology, 97, 38-41 [PMID:2566551 DOI:10.1016/0016-5085(89)91412-1]

Allgayer, H., Hofer, P., Schmidt, M., Bohne, P., Kruis, W., Gugler, R. (1992). Superoxide, hydroxyl and fatty acid radical scavenging by aminosalicylates. Direct evaluation with electron spin resonance spectroscopy. Biochem Pharmacol, 43, 259262 [https://doi.org/10.1016/0006-2952(92)90286-R]

Bergman, R., Parkes, M. (2006). Systematic review: the use of mesalazine in inflammatory bowel disease. Aliment Pharmacol Ther, 23, 841- 855 [PMID:16573787 DOI:10.1111/j.1365-2036.2006.02846.x ]

Brøsen, K. (2004). Some aspects of genetic polymorphism in the biotransformation of antidepressants. Therapie, 59, 5-12 [PMID:15199661 https://www.ncbi.nlm.nih.gov/pubmed/15199661]

$\mathrm{Bu}$, H. -Z. (2006). A literature review of enzyme kinetic parameters for CYP3A4- mediated metabolic reactions of 113 drugs in human liver microsomes: structure-kinetics relationship assessment. Curr Drug Metab, 7, 231-249 [PMID:16611019 https://www.ncbi.nlm.nih.gov/pubmed/16611019]

Burke, M.D., Mayer, R.T. (1974) Ethoxyresorufin. direct fluorimetric assay of a microsomal O-dealkylation which is preferentially inducible by 3-methylchlontrane. Drug Metab Dispos 2:583-588 [PMID:4155680

https://www.ncbi.nlm.nih.gov/pubmed/4155680]

Cochin, J., Axelrod, J. (1959) Bichemical and pharmacological changes in the rat following chronic administration of morphine, nalorphine, and normorphine. J Pharm Exp Ther 125:105-110 [PMID:13631608

https://www.ncbi.nlm.nih.gov/pubmed/13631608 ]

Dilger, K., Trenk, D., Rossle, M., Cap, M., Zahringer, A., Wacheck, V., Remmler, C., Cascorbi, I., Kreisel, W., Novacek, G. (2007). A clinical trial on absorption and N-acetylation of oral and rectal mesalazine. Eur J Clin Invest, 37, 558-565 [PMID:17576207 DOI:10.1111/j.1365-2362.2007.01809.x]

Egan, LJ., Mays, DC., Huntoon, CJ. (1999). Inhibition of interleukin-1- stimulated NF-kappaB RelA/p65 phosphorylation by mesalamine is accompanied by decreased transcriptional activity. J Biol Chem,274, 26448- 26453 [PMID:10473604 DOI: $10.1074 / j b c .274 .37 .26448]$

Everhart, J. (2008).Inflammatory bowel diseases. The Burden of Digestive Diseases in the United States, edited by Everhart J. Washington, DC: US Government Printing Office [https://www.niddk.nih.gov/about-niddk/strategic-plans-reports/burdenof-digestive-diseases-in-united-states]

Galvez, J., Garrido, M., Rodriguez-Cabezas, ME. (2003). The intestinal anti-inflammatory activity of UR-12746S on reactivated experimental colitis is mediated through downregulation of cytokine production. Inflammatory Bowel Dis, 9, 363-371 [https://doi.org/10.1097/00054725-200311000-00004] 
Guengerich, F. P. (2008). Cytochrome P450 and chemical toxicology. Chem Res Toxicol, 21, 70-83 [PMID:18052394 DOI:10.1021/tx700079z ]

Hamdon, EA., Zakaria, S.A., AL-Hamdany, N.M . (2011). Spectrophotometric Determination of Mesalazine with Phloroglycinol in Pharmaceutical Preparation. Tikrit Journal of Pure Science, 17 (2), 1813 - 1662 [https://www.iasj.net/iasj?func=fulltext\&aId=62107]

Hawkey, CJ., Boughton-Smith, NK., Whittle, BJ. (1985). Modulation of human colonic arachidonic acid metabolism by sulfasalazine. Dig Dis Sci, 30, 1161-1165 [PMID:2866075 DOI:10.1007/bf01314051]

Hendrychová, T., Anzenbacherová, E., Hudeček, J., Skopalík, J., Lange, R., Hildebrandt, P., et al. (2011). Flexibility of human cytochrome P450 enzymes: molecular Dynamics and spectroscopy reveal important function-related variations. Biochim Biophys Acta, 1814, 58-68 [PMID:20656072 DOI:10.1016/j.bbapap.2010.07.017]

Hiemke, C., and Härtter, S. (2000). Pharmacokinetics of selective serotonin reuptake inhibitors. Pharmacol Ther, 85, 11-28 [PMID:10674711 https://www.ncbi.nlm.nih.gov/pubmed/10674711]

Horvath, K., Varga, C., Berko, A., Posa, A., Laszlo, F., Whittle, B.J. (2008) The involvement of heme oxygenase-1 activity in the therapeutic actions of 5-aminosalicylic acid in rat colitis. Eur J Pharmacol 581, 315-323 [PMID:18215658 DOI:10.1016/j.ejphar.2007.12.004]

Ireland, A., Priddle, JD., Jewell, DP. (1990). Acetylation of 5-aminosalicylic acid by isolated human colonic epithelial cells. Clin Sci (Lond), 78, 105-11 [PMID:2153487 DOI:10.1042/cs0780105]

Kim, Y. H., Bae, Y.J ., Kim, H. S. et al. (2015). Measurement of human cytochrome P450 enzyme induction based on mesalazine and mosapride citrate treatments using a luminescent assay. Biomol Ther, 23, 486-92 [PMID:26336590 DOI:10.4062/biomolther.2015.041]

Küpfer, A., and Preisig, R. (1984). Pharmacogenetics of mephenytoin: a new drug hydroxylation polymorphism in man. Eur J Clin Pharmacol, 26, 753-759 [PMID:6489416 DOI:10.1007/bf00541938]

Lee, C. R., Goldstein, J. A., and Pieper, J. A. (2002). Cytochrome P450 2C9 polymorphisms: a comprehensive review of the in-vitro and human data. Pharmacogenetics, 12, 251-263 [PMID:11927841 https://www.ncbi.nlm.nih.gov/pubmed/11927841]

Liu, Y. -T., Hao, H. -P., Liu, C. -X., Wang, G. -J., \& Xie, H. -G. (2007). Drugs as CYP3A probes, inducers, and inhibitors. Drug Metab Rev, 39, 699-721 [PMID:18058330 DOI:10.1080/03602530701690374]

Loftus, EV. Jr. (2004).Clinical epidemiology of inflammatory bowel disease: Incidence, prevalence, and environmental influences. Gastroenterology, 126, 1504-1517 [PMID:15168363 DOI:10.1053/j.gastro.2004.01.063]

Nash, T. (1953) The colorimetric estimation of formaldehyde by means of the Hantzsch reaction. Biochem J 55:416-421 [PMID: 13105648 DOI: 10.1042/bj0550416]

Nelson, D. R., Zeldin, D. C., Hoffman, S. M. G., Maltais, L. J., Wain, H. M., and Nebert, D. W. (2004). Comparison of cytochrome P450 (CYP) genes from the mouse and human genomes, including nomenclature recommendations for genes, pseudogenes and alternative-splice variants. Pharmacogenetics, 14, 1-18 [PMID:15128046 https://www.ncbi.nlm.nih.gov/pubmed/15128046]

Nielsen, OH., Munck, LK. (2007). Drug insight: aminosalicylates for the treatment of IBD. Nat Clin Pract Gastroenterol Hepatol, 4,160-170 [PMID:17339853 DOI:10.1038/ncpgasthep0696 ]

Nielsen, OH., Verspaget, HW., Elmgreen, J. (1988). Inhibition of intestinal macrophage chemotaxis to leukotriene B4 by sulphasalazine, olsalazine, and 5-aminosalicylic acid. Alimen Pharmacol Ther2, 203-211 [PMID:2908754 https://www.ncbi.nlm.nih.gov/pubmed/2908754]

Nobilis, M., Vyb'iralova', Z.,Sl'adkov'a, K., L'1sa, M., Hol`capek, M., Kvetina, J. (2006). High-performance liquid chromatographic determination of 5-aminosalicylic acid and its metabolites in blood plasma. J. Chromatogr. A, 1119, 299308 [PMID:16466733 DOI:10.1016/j.chroma.2006.01.058]

Owena, RP., Sangkuhla, K., Kleina T.E, and Altmana, RB. (2009). Cytochrome P450 2D6. PharmacogenetGenomics. 19 (7), 559-562 [PMID:19512959 DOI:10.1097/FPC.0b013e32832e0e97]

Reifen, R., Nissenkorn, A., Matas, Z., Bujanover, Y. (2004). 5-ASA and lycopene decrease the oxidative stress and inflammation induced by iron in rats with colitis. J Gastroenterol, 39, 514-519 [PMID:15235867 DOI:10.1007/s00535-0031336-z]

Rettie, A. E., and Jones, J. P. (2005). Clinical and toxicological relevance of CYP2C9: Drug-drug interactions and pharmacogenetics. Annual Review of Pharmacology and Toxicology, 45, 477-494 [PMID:15822186 DOI:10.1146/annurev.pharmtox.45.120403.095821]

Rousseaux, C., Lefebvre, B., Dubuquoy, L., Lefebvre, P., Romano, O., Auwerx, J., Metzger, D., Wahli, W., Desvergne, B., Naccari, G. C., Chavatte, P., Farce, A., Bulois, P., Cortot, A., Colombel, J. F., Desreumaux, P. (2005) Intestinal antiinflammatory effect of 5-aminosalicylic acid is dependent on peroxisome proliferator-activated receptor-gamma. J Exp Med, 201, 1205-1215 [PMID:15824083 DOI:10.1084/jem.20041948]

Scott, E. E., and Halpert, J. R. (2005). Structures of cytochrome P450 3A4. Trends Biochem Sci, 30, 5-7 [PMID:15653318 DOI:10.1016/j.tibs.2004.11.004]

Shimada, T., Yamazaki, H., Mimura, M., Inui, Y., and Guengerich, F. P. (1994). Interindividual variations in human liver cytochrome P-450 enzymes involved in the oxidation of drugs, carcinogens and toxic chemicals: studies with liver microsomes of 30 Japanese and 30 Caucasians. J Pharmacol Exp Ther, 270, 414-423 [PMID:8035341 https://www.ncbi.nlm.nih.gov/pubmed/8035341] 
Stingl, J. C., Brockmöller, J., and Viviani, R. (2013). Genetic variability of drug metabolizing enzymes: the dual impact on psychiatric therapy and regulation of brain function. Mol Psychiatry,18, 273-287 [PMID:22565785 DOI:10.1038/mp.2012.42]

Tjornelund, J., Hansen, SH., Cornett, C. (1991). New metabolites of the drug 5-aminosalicylic acid. II. N-formyl-5aminosalicylic acid. Xenobiotica, 21, 605-612 [PMID:1949893 DOI:10.3109/00498259109039500]

Wang, B., Zhou, SF. (2009). Synthetic and natural compounds that interact with human cytochrome P450 1A2 and implications in drug development. Curr Med Chem, 16 (31), 4066-4218 [PMID: 19754423 https://www.ncbi.nlm.nih.gov/pubmed/19754423]

Watkinson, G. (1986). Sulphasalazine: a review of 40 years' experience. Drugs, 32(1), 1-11 [PMID:2877847 DOI:10.2165/00003495-198600321-00003]

Yasar, I., Ozyurt, R., Todurga, Z.G., Celik, G., Arslan, S., Sen, A. (2011). Diverse action of 5-aminosalicylic acid on cytochrome P450 expression in human cervical cancer cell line. FEBS Journal, 239, 74-445

[https://febs.onlinelibrary.wiley.com/doi/epdf/10.1111/j.1742-4658.2011.08137.x]

Zanger, U. M., and Hofmann, M. H. (2008). Polymorphic cytochromes P450 CYP2B6 and CYP2D6: recent advances on single nucleotide polymorphisms affecting splicing. Acta Chim Slov, 55, 38 [http://acta-arhiv.chem-soc.si/55/55-1-38.pdf]

Zanger, U.M., Turpeinen, M., Klein, K., and Schwab, M. (2008). Functional pharmacogenetics/ genomics of human cytochromes P450 involved in drug biotransformation. Anal Bioanal Chem, 392, 1093-1108 [PMID:18695978 DOI:10.1007/s00216-008-2291-6 ] 